\title{
Lipid storage droplet protein 5 reduces sodium palmitate-induced lipotoxicity in human normal liver cells by regulating lipid metabolism-related factors
}

\author{
XUEQIANG MA*, FEIYONG CHENG* , KEYU YUAN, KEXIANG JIANG and TIEMING ZHU \\ Department of Hepatobiliary Surgery, Zhuji People's Hospital of Zhejiang Province, Zhuji, Zhejiang 311800, P.R. China
}

Received April 24, 2018; Accepted November 28, 2018

DOI: $10.3892 / \mathrm{mmr} .2019 .10360$

\begin{abstract}
Lipid storage droplet protein 5 (LSDP5) is specifically expressed in tissues with high oxidative metabolism such as liver and heart. The present study aimed to explored the role of LSDP5 in sodium palmitate-induced lipotoxicity in LO2 normal human liver cells. LO2 cells were treated with various concentrations of sodium palmitate $(25,50,75,100,125$ and $150 \mu \mathrm{mol} / \mathrm{l}$ ) for 12,24 and $48 \mathrm{~h}$, and cell viability was determined by Cell Counting Kit-8. Subsequently, LO2 cells were exposed to $100 \mu \mathrm{mol} / \mathrm{l}$ sodium palmitate for $48 \mathrm{~h}$ to induce lipotoxicity (Model). Lipotoxicity Model LO2 cells were also transfected with pCMV5-LSDP5 overexpression vector, and reactive oxygen species (ROS) production, mitochondrial membrane potential (MMP) and apoptotic rates were measured. The contents of non-esterified fatty acid (NEFA), malondialdehyde (MDA) and superoxide dismutase (SOD) were also measured. The expression levels of LSDP5, and apoptosis-, mitochondrial-, lipid metabolism-related factors were detected using reverse transcription-quantitative polymerase chain reaction and western blot assays. The results indicated that sodium palmitate exposure inhibited cell viability and induced lipotoxicity in LO2 cells. LSDP5 overexpression decreased ROS and apoptotic rates, and reduced NEFA and MDA content. LSDP5 transfection rescued the loss of MMP and elevated SOD content in lipotoxicity Model LO2 cells. In addition, LSDP5 upregulated the expression levels of B-cell lymphoma-2, acetyl-CoA carboxylase1/2 and fatty acid synthase (Fas), whereas the expression levels of activated-caspase-3, Bcl-2-associated X protein, cytochrome $c$, cytochrome $c$ oxidase subunits IV, carnitine palmitoyltransferase 1a and peroxisome proliferator-activated receptors $\alpha$
\end{abstract}

Correspondence to: Dr Tieming Zhu, Department of Hepatobiliary Surgery, Zhuji People's Hospital of Zhejiang Province, 9 Jianming Road, Taozhu Street, Zhuji, Zhejiang 311800, P.R. China

E-mail: zhutieming_tmz@163.com

*Contributed equally

Key words: lipid storage droplet protein 5, sodium palmitate, lipotoxicity, human normal liver cells levels were downregulated. LSDP5 may produce a protective effect on sodium palmitate-induced lipotoxicity in LO2 cells by regulating lipid metabolism-related factors.

\section{Introduction}

Non-alcoholic fatty liver disease (NAFLD) is a clinicopathological syndrome that is characterized by fatty deposits in the liver cells; it is caused by genetic, environmental and metabolic stress-associated factors (1). In China, the incidence of NAFLD is increasing, and NAFLD is one of the major diseases that seriously threatens public health (2); NAFLD is able to cause hepatocellular carcinoma $(3,4)$. The prevalence of NAFLD is $17-33 \%$ in the Americas and the prevalence of nonalcoholic steatohepatitis (NASH), a type of NAFLD, accounts for $\sim 10-20 \%$. Noticeably, the incidence rate of cirrhosis among patients with NASH, within 10-15 years, reaches as high as $15-25 \%(5,6)$. At present, it is believed that the core factor leading to NASH is lipotoxicity (7).

A number of studies have demonstrated that free fatty acid (FFA) produce a toxic effect, which contributed to liver cell dysfunction and apoptosis (8-10). When the level of FFA exceeds the oxidative and metabolic capacity of the liver, lipids accumulate in the liver and inflammatory factors are released, subsequently initiating apoptotic signals, increasing the sensitivity of hepatocytes to inflammatory reactions and various injury factors. This damage will ultimately lead to hepatocellular dysfunction or death that is called lipotoxicity $(11,12)$. In liver cells, excessive amounts of fatty acids are mainly stored in lipid droplets (LD) (13); therefore, the abnormal metabolism of LD is closely related to lipotoxicity.

LD are a major storage site for neutral lipids in cells, and are widely found in bacteria, fungi, plants and animals $(14,15)$. LD is considered a simple structure of energy storage; however, it has been reported that LD serves a role in diseases, including obesity and fatty liver (16). Structurally, LD is composed of neutral lipid and phospholipid, which contains many LD-related proteins embedded in the phospholipid monolayer; according to previous studies, these proteins serve a vital role in maintaining the stability and metabolic processes of LD $(17,18)$. Lipid storage droplet protein 5 (LSDP5; also known as myocardial lipid droplet protein or oxidative tissue-enriched PAT protein) is mainly distributed in tissues with high oxidative metabolism, such as liver, heart 
and skeletal muscle (19-21). In addition, LSDP5 is a member in PAT family of lipid droplet proteins (19). A number of previous studies have reported PAT family proteins serve a regulatory role in lipid droplet metabolism and in maintaining lipid balance in cells $(22,23)$. However, the specific function and mechanism of LSDP5 in hepatocellular lipid metabolism is still not fully understood.

In the present study, it was hypothesized that LSDP5 may produce a protective effect on the liver cells with lipotoxicity by regulating lipid metabolism. An in vitro model of lipotoxicity was established by treating LO2 normal human liver cells with sodium palmitate. The effects of LSDP5 on lipid metabolism, oxidative stress, apoptosis and mitochondrial function in sodium palmitate-induced LO2 cells were examined.

\section{Materials and methods}

Cell culture. LO2 normal human liver cells were purchased from Procell Life Technology Co., Ltd. (Wuhan, China). Cells were cultured in Dulbecco's modified Eagle's medium (DMEM; Huayueyang Biology, Beijing, China) that contained $10 \%$ foetal bovine serum (HyClone; GE Healthcare Life Sciences, Logan, UT, USA) and $100 \mathrm{U} / \mathrm{ml}$ streptomycin and $100 \mu \mathrm{g} / \mathrm{ml}$ penicillin (Beijing Solarbio Science \& Technology Co., Ltd., Beijing, China) in a Forma $\mathrm{CO}_{2}$ incubators (Thermo Fisher Scientific, Inc., Waltham, MA, USA) with $5 \% \mathrm{CO}_{2}$ at $37^{\circ} \mathrm{C}$.

Preparation of sodium palmitate solution. Solid sodium palmitate was purchased from Heowns Biochemical Technology Co., Ltd. (Tianjin, China). The sodium palmitate was dissolved in BSA solution, which was subsequently diluted in DMEM; the final concentrations of sodium palmitate were $25,50,75$, 100,125 and $150 \mu \mathrm{mol} / 1$.

Cell transfection and treatment. The pCMV5-LSDP5 and pCMV5-NC plasmids were obtained from Genewiz Inc. (Suzhou, China). LO2 cells $\left(1 \times 10^{5} \mathrm{ml}\right)$ were transfected with $2 \mu \mathrm{g}$ of pCMV5-LSDP5 or pCMV5-NC plasmid using Lipofectamine ${ }^{\circledR} 2000$ transfection reagent (Thermo Fisher Scientific, Inc.). The experiments comprised four groups: i) Control group, which was treated with $0.1 \%$ PBS; ii) Model group, which was treated with $100 \mu \mathrm{mol} / 1$ sodium palmitate; iii) Model + negative control $(\mathrm{M}+\mathrm{NC})$ group, which was treated with $100 \mu \mathrm{mol} / 1$ sodium palmitate transfected with pCMV5-NC plasmid and ; and iv) Model + LSDP5 group (M + LSDP5), which was transfected with pCMV5-LSDP5 plasmid and treated with $100 \mu \mathrm{mol} / 1$ sodium palmitate at $37^{\circ} \mathrm{C}$ for $24 \mathrm{~h}$.

Cell Counting Kit-8 (CCK-8) viability assay. CCK-8 (Beijing Saichi Biological Technology Co., Ltd., Beijing, China) was used to detect cell viability, following the manufacturer's protocol. Briefly, cells $\left(3.5 \times 10^{3}\right.$ cells/well $)$ were cultured in 96-well plates in a humidified incubator with $5 \% \mathrm{CO}_{2}$ at $37^{\circ} \mathrm{C}$. Following a protocol from a previous study (24), cells were treated with sodium palmitate at $25,50,75,100$, 125 or $150 \mu \mathrm{mol} / \mathrm{l}$ and incubated for 12,24 or $48 \mathrm{~h}$. Following incubation, CCK-8 reagent was added into each well and the cells were incubated in humidified environment with $5 \% \mathrm{CO}_{2}$ at $37^{\circ} \mathrm{C}$ for $2 \mathrm{~h}$. Absorbance was measured at $450 \mathrm{~nm}$ using a SpectraMax iD3 microplate reader (Molecular Devices, LLC, Sunnyvale, CA, USA).

Non-esterified fatty acid (NEFA) assay. The content of NEFA was measured using a NEFA Detection kit (Wako Pure Chemical Industries, Ltd., Osaka, Japan), following the manufacturer's protocol. Briefly, cells were treated with drugs and grouped as aforementioned. Following treatments, $22 \mu \mathrm{M}$ $\left[9,10-{ }^{3} \mathrm{H}\right]$ oleate was added to cells for $4 \mathrm{~h}$. Cells were subsequently washed two times with PBS and cultured in DMEM for $4 \mathrm{~h}$. The cells were digested with $0.25 \%$ EDTA-trypsin (Beijing Solarbio Science \& Technology Co., Ltd.), resuspended in DMEM and centrifuged with 1,000 x g for $10 \mathrm{~min}$. The supernatant was transferred into a clean centrifuge tube. Lipid was extracted from supernatant using N-hexane: Isopropanol solution (3:2) and a thin layer chromatography silica gel plate (25). The silica gel of containing NEFA fraction was scraped from the silica gel plate and dissolved in N-hexane: Isopropanol solution (3:2). Scintillation solution was added and the ${ }^{3} \mathrm{H}$-labeled NEFA protein content in the cells was measured using a L6500 liquid scintillation counter (Beckman Coulter, Inc., Brea, CA, USA). NEFA protein concentration was detected using a Bradford protein assay kit (Beyotime Institute of Biotechnology, Haimen, China).

Cell apoptosis assay. An Annexin V-fluorescein isothiocyanate (FITC)/propidium iodide (PI) Apoptosis Detection kit (Sigma-Aldrich; Merck KGaA, Darmstadt, Germany) was used to determine the rates of cell apoptosis, following the manufacturer's protocol. Briefly, cells $\left(5 \times 10^{4}\right.$ cells/well) were cultured overnight in 6-well plates in a humidified incubator with $5 \% \mathrm{CO}_{2}$ at $37^{\circ} \mathrm{C}$. Cells were treated with drugs and grouped as aforementioned. The cells were washed two times with cold PBS, centrifuged at $300 \mathrm{x}$ g at $4^{\circ} \mathrm{C}$ for $5 \mathrm{~min}$ and resuspended in 1X Binding Buffer. Subsequently, the cells were stained with Annexin V-FITC/PI staining solution in the dark at room temperature for 10-15 min. Apoptotic cells were detected using an A28999 flow cytometer (Thermo Fisher Scientific, Inc.) and analyzed with BD CellQuest ${ }^{\mathrm{TM}}$ Pro Software version 1.2; BD Biosciences, San Jose, CA, USA).

Reactive oxygen species (ROS) assay. ROS activity was determined with a ROS assay kit (Beyotime Institute of Biotechnology), following the manufacturer's protocol. Briefly, cells were treated with drugs and grouped, as aforementioned. Subsequently, the cells were incubated with 2',7'-dichlorofluorescein diacetate at $37^{\circ} \mathrm{C}$ for $25 \mathrm{~min}$. The cells were washed three times with PBS, and ROS was detected using a flow cytometer and analyzed by Summit Software V4.3 (Dako; Agilent Technologies, Inc., Santa Clara, CA, USA).

Mitochondrial membrane potential (MMP) assay. MMP was measured using a JC-1 kit(Beyotime Institute of Biotechnology), following the manufacturer's protocol. Briefly, cells were treated with drugs and grouped, as aforementioned. Following treatments, cells were digested with $0.25 \%$ EDTA-trypsin, re-suspended in DMEM and stained with JC-1 solution at $37^{\circ} \mathrm{C}$ for $20 \mathrm{~min}$. Subsequently, cells were centrifuged at $600 \mathrm{x} \mathrm{g}$ at $4^{\circ} \mathrm{C}$ for $3 \mathrm{~min}$. The supernatant was discarded and cells were 
washed two times with PBS. MMP was detected by a flow cytometer with analysis software version 1.2 (BD CellQuest ${ }^{\mathrm{TM}}$ Pro Software; BD Biosciences).

ELISA. Levels of oxidative stress-related factors were respectively measured using an MDA Elisa kit (cat. no. E-EL-0060c, Elabscience, Wuhan, China) and an SOD ELISA kit (cat. no. S0109; Beyotime Institute of Biotechnology), following the protocols of the manufacturer. Briefly, cells were treated with drugs and grouped, as aforementioned. Following treatments, cells were digested with $0.25 \%$ EDTA-trypsin, centrifuged at $800 \mathrm{x} \mathrm{g}$ for $6 \mathrm{~min}$. The cells $\left(1 \times 10^{6} \mathrm{ml}\right)$ were re-suspended in DMEM and added to wells at $37^{\circ} \mathrm{C}$ for $24 \mathrm{~h}$. A total of $100 \mu \mathrm{l}$ biotinylated antibody (included in kits) was added and the cells were incubated at $37^{\circ} \mathrm{C}$ for $30 \mathrm{~min}$. Cells were washed three times with PBS, followed by the addition of the termination solution into wells. Absorbance was measured at $450 \mathrm{~nm}$ using a microplate reader (SkanIt software V3.1, Thermo Fisher Scientific, Inc.).

Reverse transcription-quantitative polymerase chain reaction $(R T-q P C R)$. Cells were treated with drugs and grouped, as aforementioned. Total RNA was extracted using TRIzol ${ }^{\circledR}$ Reagent (Takara Biotechnology Co., Ltd., Dalian, China). RNA $(1 \mu \mathrm{g})$ was used to synthesize cDNA using an RT Master Mix kit (Takara Biotechnology Co., Ltd.) and the following parameters: $85^{\circ} \mathrm{C}$ for $15 \mathrm{~min}$, followed by $4^{\circ} \mathrm{C}$ for $10 \mathrm{~min}$. SYBR Premix Taq II kit (Takara Biotechnology Co., Ltd.) was used for amplifying cDNA, and the $50 \mu \mathrm{l}$ reactions were set up as follows: $25 \mu 1 \mathrm{SYBR}-G$ reen Mix, $1 \mu \mathrm{l}$ forward/reverse primers (Table I), $19 \mu \mathrm{l} \mathrm{ddH}_{2} \mathrm{O}$ and $4 \mu \mathrm{l} \mathrm{cDNA}$. PCR thermocycling conditions were: $85^{\circ} \mathrm{C}$ for $15 \mathrm{~min}$; followed by 30 cycles at $85^{\circ} \mathrm{C}$ for $20 \mathrm{sec}$ and $65^{\circ} \mathrm{C}$ for $45 \mathrm{sec}$; and $85^{\circ} \mathrm{C}$ for $20 \mathrm{sec}$, at $37^{\circ} \mathrm{C}$ for $2 \mathrm{~min}$. $\beta$-actin was used as a loading control for the normalization of expression. The formula $2^{-\Delta \Delta \mathrm{Cq}}$ was used to calculate relative mRNA expression levels (26).

Western blot assay. Cells were treatment as aforementioned and subsequently washed twice with PBS, lysed in Radioimmunoprecipitation Assay Buffer (high) (Beijing Solarbio Science \& Technology Co., Ltd.) to obtain protein extracts. Protein concentrations were detected by a Bradford protein assay kit. Proteins $(20 \mu \mathrm{g} /$ lane $)$ were separated by $10 \%$ SDS-PAGE. Proteins were transferred to polyvinylidene fluoride membranes (Hangzhou Renomem Technology Co., Ltd., Hangzhou, China). Subsequently, the membranes were blocked in $5 \%$ non-fat milk for $2 \mathrm{~h}$ at room temperature. The membranes were incubated with primary antibodies against LSDP5 (1:1,000; cat. no. ab222811; Abcam, Cambridge, UK), active-caspase-3 (1:2,000; cat. no. AF-605-NA; R\&D Systems, Inc.,Minneapolis,MN,USA),B-cell lymphoma-2 (Bcl-2; 1:800; cat. no. AF810; R\&D Systems, Inc.), Bcl-2-associated X protein (Bax; 1:1,000; cat. no. AF820; R\&D Systems, Inc.,), cytochrome $c$ (Cytc; 1:1,000; cat. no. MAB897; R\&D Systems, Inc.), Cytc oxidase subunits IV (Cox IV; 1:1,200; cat. no. MAB6980; R\&D Systems, Inc.), carnitine palmitoyltransferase 1a (CPT1a; 1:1,200; cat. no. ab83862; Abcam), acetyl-co A carboxylase1 (ACC1; 1:1,000; cat. no. 4190; Cell Signaling Technology, Inc., Danvers, MA, USA), ACC2 (1:1,000; cat. no. 8578; Cell Signaling Technology, Inc.), anti-Fas (1:1,000, cat. no. 3180; Cell
Table I. Sequences of forward and reverse primers used for reverse transcription-quantitative polymerase chain reaction.

\begin{tabular}{|c|c|}
\hline Gene & Primer sequence $\left(5^{\prime} \rightarrow 3^{\prime}\right)$ \\
\hline LSDP5 & $\begin{array}{l}\text { F: GTGATCAGACAGCTCAGGACCC } \\
\text { R: CGATTCACCACATTCTGCTG }\end{array}$ \\
\hline Active-caspase-3 & $\begin{array}{l}\text { F: TGCCCAAGTGACTGACATCA } \\
\text { R: CATCCCCATTGACTGTGCAG }\end{array}$ \\
\hline Bax & $\begin{array}{l}\text { F: GACCCGGTGCCTCAGGATGC } \\
\text { R: AGGTCAGCTCATCATGCTTG }\end{array}$ \\
\hline Bcl-2 & $\begin{array}{l}\text { F: GTGGAGGAGCTCTTCAGGGA } \\
\text { R: GTCTGTGTCCACGGCGGCAA }\end{array}$ \\
\hline Cytc & $\begin{array}{l}\text { F: CCAAATCTCCACGGTCTGTTC } \\
\text { R: ATCAGGGTATCCTCTCCCCAG }\end{array}$ \\
\hline Cox IV & $\begin{array}{l}\text { F: CGGCGTGACTACCCCTTG } \\
\text { R: TGAGGGATGGGGCCATACA }\end{array}$ \\
\hline CPT1a & $\begin{array}{l}\text { F: TGTCCAAGTATCTGGCAGTCG } \\
\text { R: CATAGCCGTCATCAGCAACC }\end{array}$ \\
\hline $\mathrm{ACC} 1$ & $\begin{array}{l}\text { F: TTTGTTTGGTCGTGACTG } \\
\text { R: CCCAGCACTCACATAACC }\end{array}$ \\
\hline $\mathrm{ACC} 2$ & $\begin{array}{l}\text { F: GACGCCCGAGGATCTGAAG } \\
\text { R: GGGACAGGGACGTACTGATC }\end{array}$ \\
\hline Fas & $\begin{array}{l}\text { F: ATGACAGGAGATGGAAGG } \\
\text { R: CTGACTTCCACCAGCAGC }\end{array}$ \\
\hline $\operatorname{PPAR} \alpha$ & $\begin{array}{l}\text { F: CGGCGTGACTACCCCTTG } \\
\text { R: TGAGGGATGGGGCCATACA }\end{array}$ \\
\hline$\beta$-actin & $\begin{array}{l}\text { F: GACTCCTATGTGGGTGACGA } \\
\text { R: ACGGTTGGCCTTAGGGTTCA }\end{array}$ \\
\hline
\end{tabular}

ACC, acetyl-co A carboxylase; Bax, Bcl-2-associated X protein; Bcl-2, B-cell lymphoma-2; Cox IV, cytochrome $c$ oxidase subunits IV; CPT1a, carnitine palmitoyltransferase 1a; Cytc, cytochrome $c$; F, forward; Fas, fatty acid synthase; LSDP5, lipid storage droplet protein 5; PPAR $\alpha$, peroxisome proliferator-activated receptors $\alpha$; $\mathrm{R}$, reverse.

Signaling Technology, Inc.), peroxisome proliferator-activated receptors $\alpha$ (PPAR $\alpha$; 1:100; cat. no. PP-H0723-00) and $\beta$-actin $\left(1: 2,000\right.$; cat. no. MAB8969) on the rocking table at $4{ }^{\circ} \mathrm{C}$ overnight. Subsequently, the membranes were washed 2-3 times with PBS and $0.05 \%$ Tween-20 for $6 \mathrm{~min}$, followed by incubation with the following horseradish peroxidase-conjugated secondary antibodies at $37^{\circ} \mathrm{C}$ for $60 \mathrm{~min}$ : Mouse anti-goat immunoglobulin G (1:7,000; cat. no. 31107; Invitrogen; Thermo Fisher Scientific, Inc.), anti-Mouse IgG Secondary Antibody (1:1,000; cat. no. HAF007; R\&D Systems, Inc.) and mouse anti-rabbit (1:7,000; cat. no. 31213; Invitrogen; Thermo Fisher Scientific, Inc.). The membranes were washed 2-3 times with PBST, and the proteins were visualized using Enhanced Chemiluminescent Detection Reagent (Taixin Biotechnology, Beijing, China). $\beta$-actin was treated as a loading control for normalization. The blot density was analyzed by Quantity One software version 4.6.2 (Bio-Rad Laboratories, Inc., Hercules, CA, USA). 

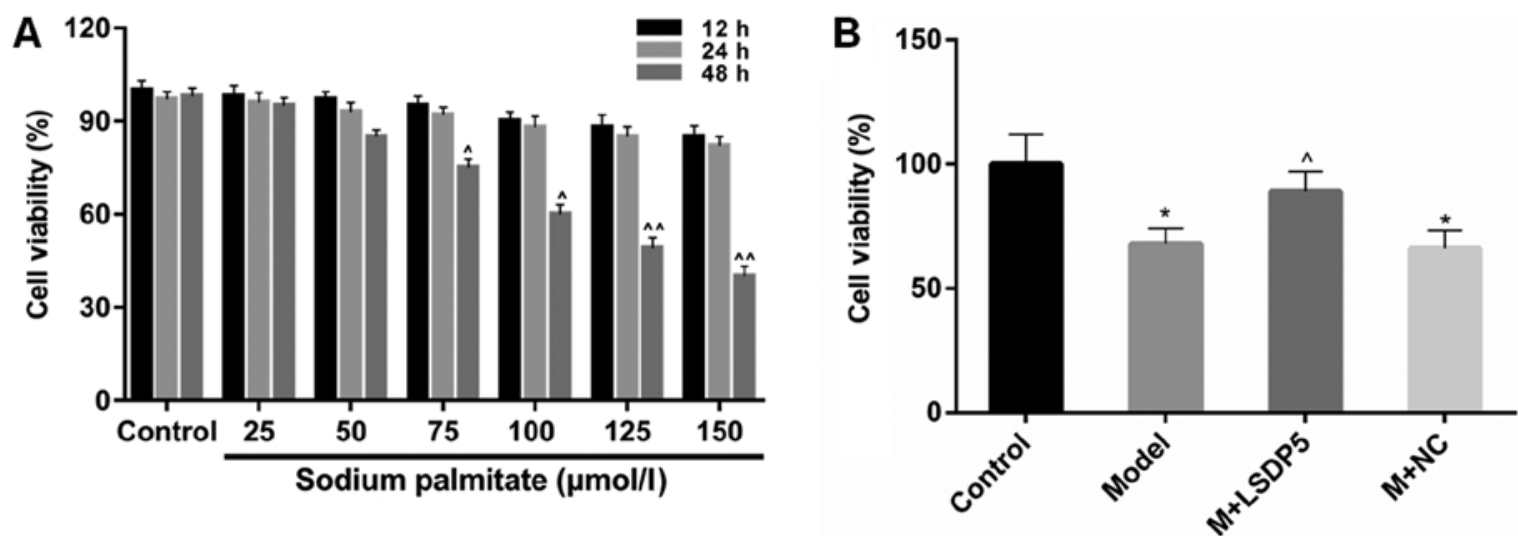

Figure 1. Sodium palmitate represses the viability of LO2 cells. (A) CCK-8 assay was performed to determine the effects of various concentrations of sodium palmitate $(25,50,75,100,125$ and $150 \mu \mathrm{mol} / \mathrm{l})$ on $\mathrm{LO} 2$ human liver cells treated for 12,24 and $48 \mathrm{~h} .{ }^{\wedge} \mathrm{P}<0.05$ and ${ }^{\wedge} \mathrm{P}<0.01$ vs. Control. (B) CCK-8 assay was used to measure the effect of LSDP5 on cell viability in LO2 cells treated with $100 \mu$ mol/1 sodium palmitate for $48 \mathrm{~h}$ (Model). "P<0.05 vs. Control; ${ }^{\wedge} \mathrm{P}<0.05$ vs. Model. LSDP5, lipid storage droplet protein 5; M, model; NC, negative control.

Statistical analysis. Data were analysed by SPSS 13.0 software (SPSS, Inc., Chicago, IL, USA); results were expressed as the mean \pm standard deviation. The differences between groups were analysed using one-way analysis of variance followed by a Dunnett's post-test. Each experiment was independently repeated in triplicate. $\mathrm{P}<0.05$ was considered to indicate a statistically significant difference.

\section{Results}

LSDP5 increases the viability of sodium palmitate-treated LO2. CCK-8 analysis was performed to examine cell viability to assess the lipotoxic effects of sodium palmitate on LO2 cells. The data revealed that viability remained relatively stable when $\mathrm{LO} 2$ cells were treated with sodium palmitate at low doses $(25$ and $50 \mu \mathrm{mol} / \mathrm{l})$ for a short period of treatment (12 and 24 h; Fig. 1A). Viability was significantly inhibited in cells treated with 125 and $150 \mu \mathrm{mol} / 1$ of sodium palmitate for $48 \mathrm{~h}$, compared with untreated control cells at the same time $(\mathrm{P}<0.01$; Fig. 1A). Treatment with $100 \mu \mathrm{mol} / 1$ sodium palmitate for $48 \mathrm{~h}$ also significantly inhibited viability, compared with the respected Control cells $(\mathrm{P}<0.05$; Fig. 1A), and this concentration and incubation time was used in subsequent experiments as the lipotoxicity Model.

Model cells were transfected with LSDP5 overexpression vectors, which resulted in a significant increase in viability compared with untransfected Model cells $(\mathrm{P}<0.05$; Fig. 1B). RT-qPCR and western blot assays were conducted to examine the LSDP5 mRNA and protein expressions levels, respectively, in LO2 Model cells transfected with pCMV5-LSDP5 plasmid (Fig. 2). The expression levels of LSDP5 mRNA and protein were significantly increased in cells transfected with pCMV5-LSDP5 (both $\mathrm{P}<0.05$; Fig. 2A and B, respectively), which indicated successful transfection of the LSDP5 overexpression vector in LO2 cells. Notably, the expression levels of LSDP5 were slightly reduced in untransfected Model cells, compared with Control cells (Fig. 2).

LSDP5 suppresses the activity of oxidative stress in LO2 lipotoxicity Model cells. Compared with Control cells, Model cells exhibited a significantly increased rate of ROS production
$(\mathrm{P}<0.001$; Fig. 3A). Although the contents of NEFA and MDA were increased $(\mathrm{P}<0.001$; Fig. 3B and $\mathrm{C}$, respectively), SOD content was decreased $(\mathrm{P}<0.001$; Fig. 3D) in Model cells compared with Control. Conversely, LSDP5 overexpression suppressed the oxidative stress of LO2 Model cells; it was also demonstrated that LSDP5 reduced the ROS level and NEFA and MDA content, and increased SOD, compared with the untransfected Model group ( $\mathrm{P}<0.05$; Fig. 3).

LSDP5 reduces apoptotic rates of LO2 Model cells. The results demonstrated that the rate of apoptosis was significantly increased $(\mathrm{P}<0.001$; Fig. $4 \mathrm{~A})$, and the expression levels of active-caspase-3 and Bax were also significantly increased in Model cells compared with Control, whereas Bcl-2 expression levels were reduced compared with Control $(\mathrm{P}<0.05$ or $\mathrm{P}<0.01$; Fig. 4B-D). In LSDP5-transfected Model cells, apoptotic rates were significantly decreased, expression levels of activated-caspase- 3 and Bax were reduced, and Bcl-2 expression levels were increased compared with the Model group $(\mathrm{P}<0.05$ or $\mathrm{P}<0.01$; Fig. 4).

LSDP5 reduces mitochondrial damage in Model cells. To examine mitochondrial activity, the rate of MMP and the expression levels of Cytc, Cox IV and CPT1A. The data indicated that sodium palmitate reduced the MMP rate of LO2 cells and increased the expression levels of Cytc, Cox IV and CPT1A, compared with Control. However, LSDP5 overexpression increased the rate of MMP and reduced Cytc, Cox IV and CPT1A expression levels compared with the untransfected Model group ( $\mathrm{P}<0.05$; Fig. 5).

LSDP5 regulates lipid metabolism-related factors in $\mathrm{LO} 2$ Model cells. RT-qPCR and western blotting assays were performed to determine the mRNA and protein expression levels, respectively, of lipid metabolism-related factors. The data indicated that the expression levels of ACC1, ACC2 and Fas were significantly decreased, whereas PPAR $\alpha$ expression levels were increased following sodium palmitate treatment, compared with Control cells $(\mathrm{P}<0.05$ or $\mathrm{P}<0.01$; Fig. 6). However, LSDP5 overexpression upregulated the expression levels of ACC1, ACC2 and Fas, and downregulated PPAR $\alpha$ 
A

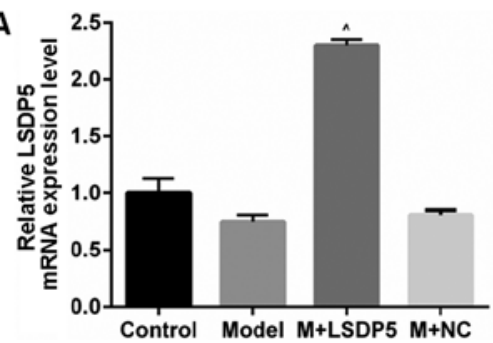

B



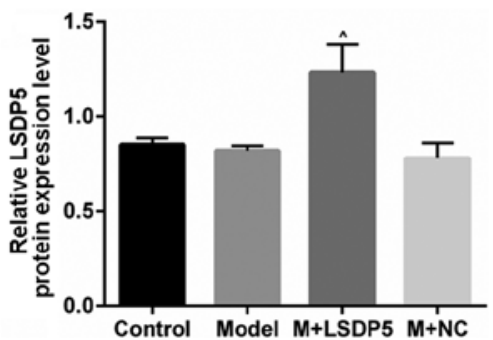

Figure 2. LSDP5 expression in LO2 cells. (A and B) Experiments were divided into Control group (0.1\% PBS treatment), Model group (100 $\mu$ mol/l sodium palmitate treatment), NC group (Model cells transfected with pCMV5-NC plasmid) and LSDP5 group (Model cells transfected with pCMV5-LSDP5 overexpression plasmid), and the (A) mRNA and (B) protein expression levels were determined reverse transcription-quantitative polymerase chain reaction and western blotting, respectively; $\beta$-actin served as an internal control and for normalization. ${ }^{\wedge} \mathrm{P}<0.05$ vs. Model. LSDP5, lipid storage droplet protein 5 ; M, model; $\mathrm{NC}$, negative control.

A
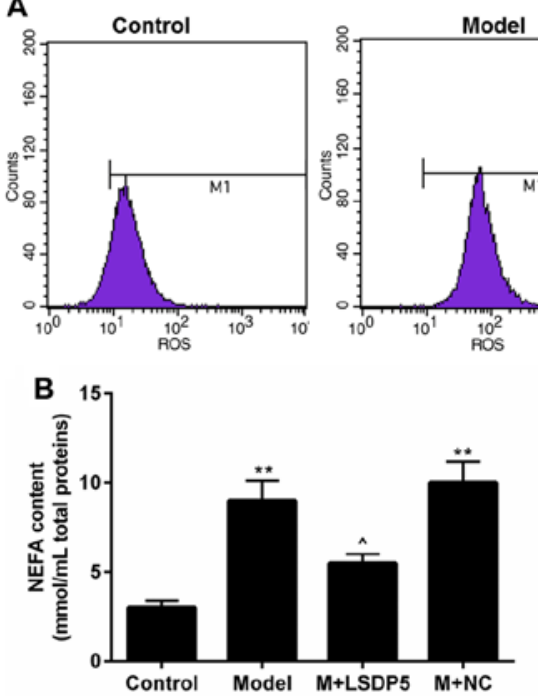



C



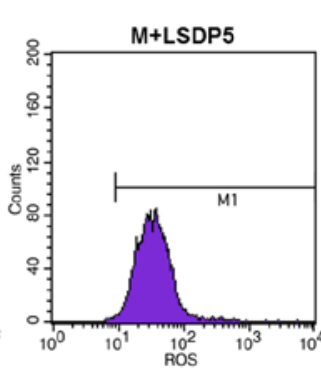

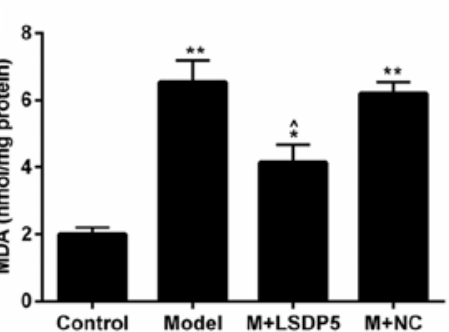

$\mathrm{M}+\mathrm{NC}$
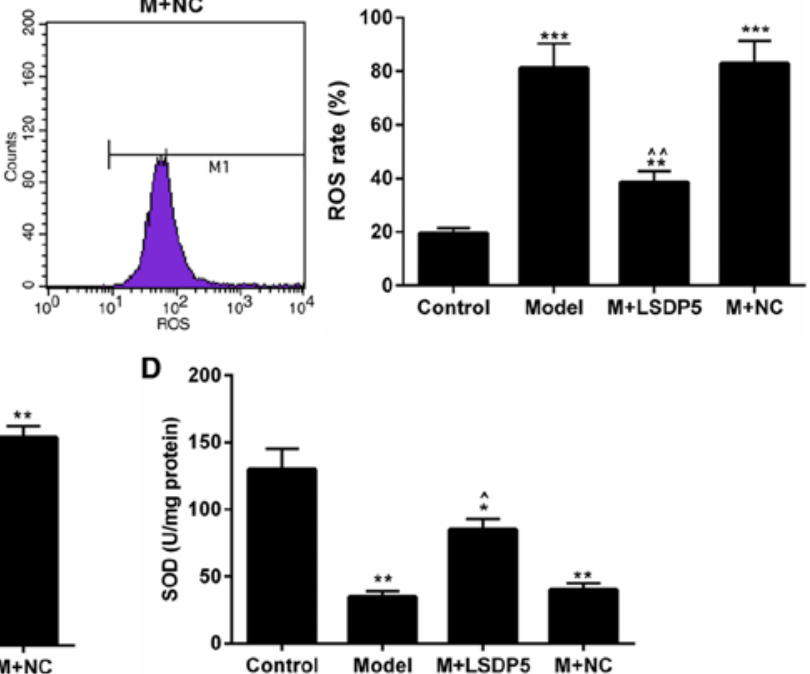

Figure 3. LSDP5 suppresses the activity of oxidative stress in LO2 lipotoxicity Model cells. (A) The rate of ROS production was measured using an ROS detection kit. (B) NEFA content was detected by NEFA detection kit. (C and D) The contents of (C) MDA and (D) SOD were analysed by ELISA. "P<0.05, ${ }^{* *} \mathrm{P}<0.01$ and ${ }^{* * * *} \mathrm{P}<0.001$ vs. Control; ${ }^{\wedge} \mathrm{P}<0.05$ and ${ }^{\wedge \wedge} \mathrm{P}<0.01$ vs. Model. LSDP5, lipid storage droplet protein 5; M, model; MDA, malondialdehyde; NC, negative control; NEFA, non-esterified fatty acid; SOD, superoxide dismutase.

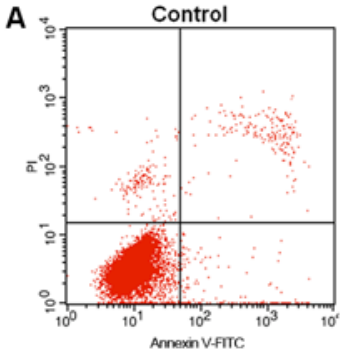

B

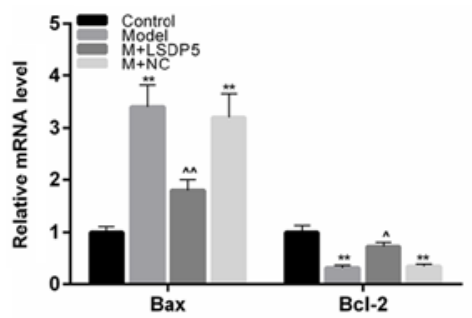

Model

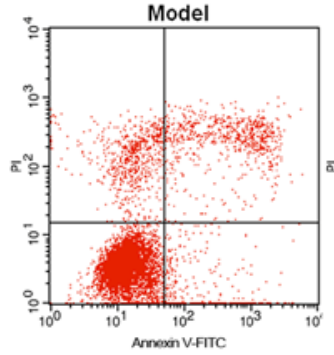

C

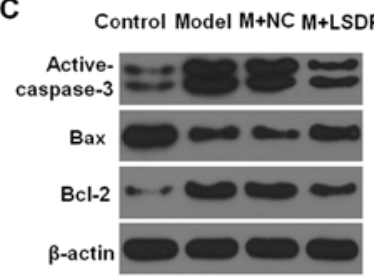

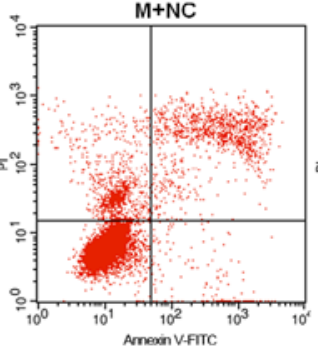
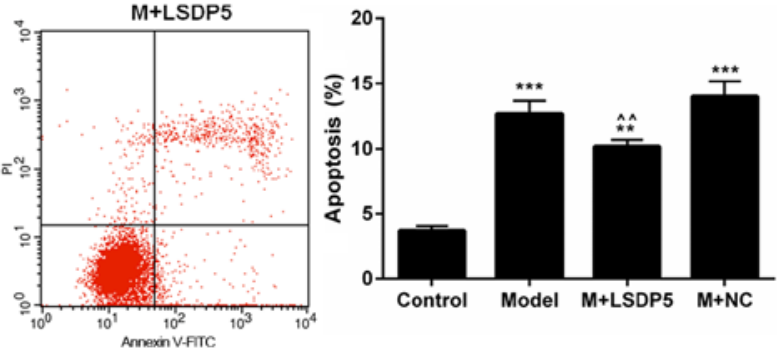

D
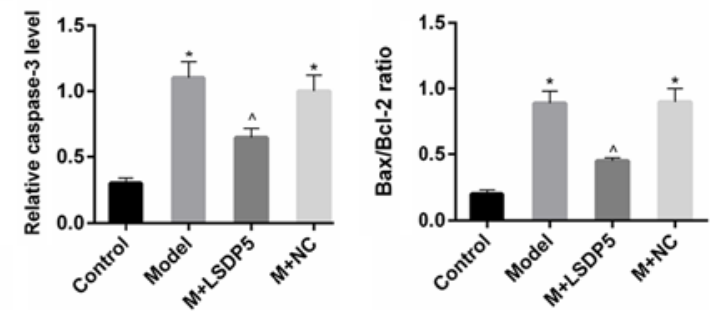

Figure 4. LSDP5 reduces apoptosis in LO2 lipotoxicity Model cells. (A) Apoptosis was detected by Annexin V-FITC/PI apoptosis detection kit. (B) mRNA expression levels of Bax and Bcl-2 were measured by reverse transcription-quantitative polymerase chain reaction. (C and D) Protein expression levels of active-caspase-3, Bax and Bcl-2 were measured by western blot assay; $\beta$-actin was used as a loading control and for normalization. ${ }^{*} \mathrm{P}<0.05,{ }^{* * *} \mathrm{P}<0.01$ and ${ }^{* * *} \mathrm{P}<0.001$ vs. Control; ${ }^{\wedge} \mathrm{P}<0.05$ and ${ }^{\wedge} \mathrm{P}<0.01$ vs. Model. Bax, Bcl-2-associated X protein; Bcl-2, B-cell lymphoma-2; FITC, fluorescein isothiocyanate; LSDP5, lipid storage droplet protein 5; M, model; NC, negative control; PI, propidium iodide. 


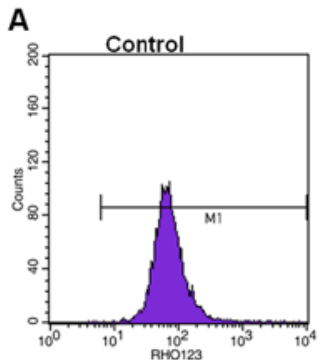

B

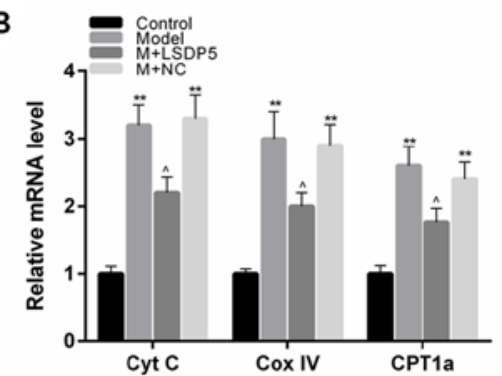


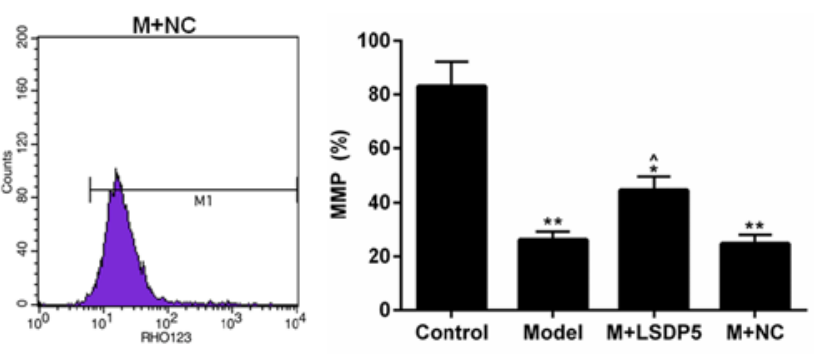

C



D

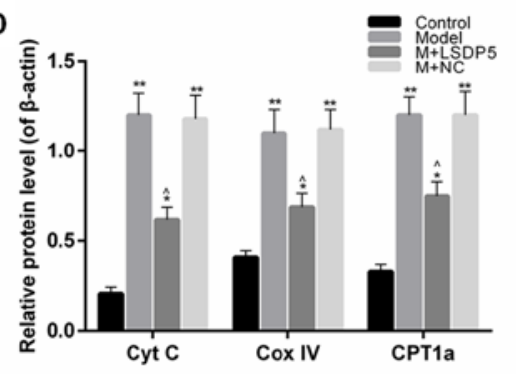

Figure 5. LSDP5 reduces mitochondrial damage in LO2 lipotoxicity Model. (A) MMP rates were detected by JC-1 kit. (B) mRNA expression levels of Cytc, Cox IV and CPT1a were measured by reverse transcription-quantitative polymerase chain reaction. (C and D) Protein expression levels of Cytc, Cox IV and CPT1a were measured by western blot assay; $\beta$-actin was used as a loading control and for normalization. ${ }^{*} \mathrm{P}<0.05$ and ${ }^{* *} \mathrm{P}<0.01$ vs. Control; ${ }^{\wedge} \mathrm{P}<0.05$ vs. Model. Cox IV, cytochrome $c$ oxidase subunit IV; CPT1a, carnitine palmitoyltransferase 1a; Cytc, cytochrome $c$; LSDP5, lipid storage droplet protein 5; M, model; MMP, mitochondrial membrane potential; NC, negative control.


Figure 6. LSDP5 regulates lipid metabolism-related factors in LO2 lipotoxicity Model cells. (A and B) ACC1, ACC2, Fas and PPAR $\alpha$ (A) mRNA and (B) protein expression levels were assessed by reverse transcription-quantitative polymerase chain reaction and western blot analysis, respectively; $\beta$-actin served as an internal control and for normalization. ${ }^{*} \mathrm{P}<0.05$ and ${ }^{* * *} \mathrm{P}<0.01$ vs. Control; ${ }^{\wedge} \mathrm{P}<0.05$ and ${ }^{\wedge} \mathrm{P}<0.01$ vs. Model. ACC, acetyl-co A carboxylase1; Fas, fatty acid synthase; LSDP5, lipid storage droplet protein 5; M, model; NC, negative control.

expression levels, compared with the untransfected Model group ( $\mathrm{P}<0.05$ or $\mathrm{P}<0.01$; Fig. 6).

\section{Discussion}

In the clinic, increased FFA levels in patients with NASH have been associated with the severity of the disease (27). Previous studies have demonstrated that sodium palmitate inhibited the viability of cells and induced lipotoxicity, which led to lipoapoptosis in liver cells $(24,28)$. In addition, oxidative stress produced by NEFA oxidation was reported to be the main mechanism of liver lipotoxicity (29,30). Mitochondrial damage is able to mediate apoptosis, which serves important roles in the pathogenesis of NASH (31). Based on these findings, the present study used sodium palmitate-treated LO2 cells to establish the lipotoxicity model. In this study, sodium palmitate was demonstrated to increase the NEFA content, and it contributed to the accumulation of oxidative stress and apoptosis, as well as mitochondrial damage in $\mathrm{LO} 2$ cells.
LSDP5 is a member of PAT family, which are specifically expressed in tissues with high oxidative metabolism. A previous report indicated that the overexpression of LSDP5 increased lipid accumulation, while that siRNA-LSDP5 promoted fatty acid oxidation in liver cells (32). Though LSDP5 deletion significantly reduces LD content, it increases ROS content in cardiomyocytes (33). Therefore, LSDP5 may produce a certain effect on fatty acid-induced lipotoxicity. LSDP5 was observed to be overexpressed in transfected with pCMV5-LSDP5 and treated with sodium palmitate LO2 cells; LSDP5 overexpression decreased NEFA content in Model LO2 cells. It was suggested that overexpression of LSDP5 may inhibit lipolysis and the accompanied liver injury. A previous study reported that the knockdown of LSDP5 may stimulate lipolysis and increase the level of fatty-acid $\beta$ oxidation (32), which may be a primary cause of liver injury (7). These data suggested that knockdown of LSDP5 accelerated the lipolysis and induced liver injury, which was consistent with the present study results. However, although these previous studies 
reported that LSDP5 promoted lipid accumulation, the present study considered that it was relative to the lipolysis by LSDP5 knockdown. Taken together, the present study results indicated that LSDP5 reduced the effect of lipotoxicity by regulating lipid metabolism-related factors.

A previous study reported that ROS may attack unsaturated fatty acids in a biofilm and enable lipid peroxidation to form end products such as MDA (34), an important index of cellular oxidative damage. SOD is also an antioxidant substance (35). The present study results demonstrated that LSDP5 reduced ROS and MDA content, and increased SOD content, which indicated that LSDP5 may suppress oxidative stress in sodium palmitate-treated LO2 cells.

Hepatocellular apoptosis was also reported to serve a vital role in the development of NASH $(36,37)$. It is known that apoptosis may cause the change of the apoptotic protein. $\mathrm{Bcl}-2$ is an indispensable anti-apoptotic gene, and Bax belongs to the Bcl-2 gene family promoting apoptosis (38). Active-caspase-3 also contributes to and can stimulate apoptosis (39). The present data indicated that LSDP5 overexpression inhibited apoptosis in lipotoxicity Model cells, and upregulated Bcl-2 expression and downregulated the levels of activated-caspase-3 and Bax. In addition, LSDP5 increased the rate of MMP and increased the expression levels of CPT1a; however, the expression levels of Cytc and Cox IV were reduced. These results suggested that LSDP5 may reduce apoptotic rates and mitochondrial damage in lipotoxicity Model LO2 cells. The results were in support of a literature that the number of mitochondria increased in LSDP5-deficient cells (32).

A previous study reported that exogenous LSDP5 increased the content of lipid in oleic acid-induced COS7 and OP9 liver cells (40). Another study suggested that LSDP5 may function to regulate the interaction between lipase and LD, and such a function is similar to perilipin, which regulated the lipolytic activity of adipocyte triglyceride lipase (41). In addition, PPAR $\alpha$ is a key regulator of lipid oxidation; LSDP5 is downstream of PPAR $\alpha$ and the upregulation of PPAR $\alpha$ may significantly increase LSDP5 expression in hepatocytes (18). ACC1, ACC2 and Fas are related to fatty acid synthesis (42). Results from the present study demonstrated that the overexpression of LSDP5 in LO2 Model cells upregulated the expression levels of ACC1, ACC 2 and Fas, and downregulated PPAR $\alpha$ expression levels; these data are consistent with a previous study, which reported that the PPAR $\alpha$ activity was increased by small interfering (si)RNA-mediated LSDP5 knockdown (32). In addition, the expression levels of $\mathrm{ACC} 1$ and Fas were not altered by si-LSDP5 in that study. Considering these findings, it was hypothesized that the downregulation of ACC1 and Fas may be a stress response when the cells were stimulated with high concentration of sodium palmitate; in this condition, the fatty acid synthesis may be inhibited.

However, the present study data were acquired using only one cell line in vitro, which was a limitation. Thus, to investigate the role of LADP5 in other cell lines or in vivo may further confirm the results from this study.

To conclude, sodium palmitate induced lipotoxicity in LO2 cells. However, overexpression of LSDP5 in lipotoxicity Model LO2 cells reduced the activity of oxidative stress and mitochondrial damage, and inhibited apoptosis by regulating lipid metabolism-related factors. These results demonstrated that LSDP5 may produce a protective effect on sodium palmitate-induced lipotoxicity in LO2 cells. However, the specific signalling pathway(s) of LSDP5 regulation of lipid metabolism remains to be further examined. This study provided a molecular basis for understanding lipotoxicity in liver, as well as a indicated a possible candidate target for treating liver lipotoxicity.

\section{Acknowledgements}

Not applicable.

\section{Funding}

No funding was received.

\section{Availability of data and materials}

The analysed data sets generated during the present study are available from the corresponding author on reasonable request.

\section{Authors' contributions}

XM and TZ made substantial contributions to the design of the present study. Data acquisition and interpretation was conducted by FC, KY and KJ. TZ and FC critically revised the manuscript for important intellectual content. All authors approved the final version of the manuscript. KY and KJ aggree to be accountable for all aspects of the work in ensuring that questions related to the accuracy or integrity of the work are appropriately investigated and resolved.

\section{Ethics approval and consent to participate}

Not applicable.

\section{Patient consent for publication}

Not applicable.

\section{Competing interests}

The authors declare that they have no competing interests.

\section{References}

1. Zheng X, Gong L, Luo R, Chen H, Peng B, Ren W and Wang Y: Serum uric acid and non-alcoholic fatty liver disease in non-obesity Chinese adults. Lipids Health Dis 16: 202, 2017.

2. Fan JG and Farrell GC: Epidemiology of non-alcoholic fatty liver disease in China. J Hepatol 50: 204-210, 2009.

3. Angulo P: GI epidemiology: Nonalcoholic fatty liver disease. Aliment Pharmacol Ther 25: 883-889, 2007.

4. de Alwis NM and Day CP: Non-alcoholic fatty liver disease: The mist gradually clears. J Hepatol 48 (Suppl 1): S104-S112, 2008.

5. Fan JG, Saibara T, Chitturi S, Kim BI, Sung JJ and Chutaputti A; Asia-Pacific Working Party for NAFLD: What are the risk factors and settings for non-alcoholic fatty liver disease in Asia-Pacific? J Gastroenterol Hepatol 22: 794-800, 2007.

6. Farrell GC and Larter CZ: Nonalcoholic fatty liver disease: From steatosis to cirrhosis. Hepatology 43 (Suppl 1): S99-S112, 2006.

7. Garbarino J and Sturley SL: Saturated with fat: New perspectives on lipotoxicity. Curr Opin Clin Nutr Metab Care 12: 110-116, 2009. 
8. Weiss TS, Lupke M, Ibrahim S, Buechler C, Lorenz J Ruemmele P, Hofmann U, Melter M and Dayoub R: Attenuated lipotoxicity and apoptosis is linked to exogenous and endogenous augmenter of liver regeneration by different pathways. PLoS One 12: e0184282, 2017.

9. Kapoor A and Sanyal AJ: Endoplasmic reticulum stress and the unfolded protein response. Clin Liver Dis 13: 581-590, 2009.

10. Bellanti F, Mitarotonda D, Tamborra R, Blonda M, Iannelli G Petrella A, Sanginario V, Iuliano L, Vendemiale G and Serviddio G: Oxysterols induce mitochondrial impairment and hepatocellular toxicity in non-alcoholic fatty liver disease. Free Radic Biol Med 75 (Suppl 1): S16-S17, 2014.

11. Kusminski CM, Shetty S, Orci L, Unger RH and Scherer PE: Diabetes and apoptosis: Lipotoxicity. Apoptosis 14: 1484-1495, 2009.

12. Unger RH and Orci L: Lipoapoptosis: Its mechanism and its diseases. Biochim Biophys Acta 1585: 202-212, 2002.

13. McCullough AJ: The clinical features, diagnosis and natural history of nonalcoholic fatty liver disease. Clin Liver Dis 8 521-533, viii, 2004.

14. Murphy DJ: The biogenesis and functions of lipid bodies in animals, plants and microorganisms. Prog Lipid Res 40: 325-438, 2001.

15. Zehmer JK, Huang Y, Peng G, Pu J, Anderson RG and Liu P: A role for lipid droplets in inter-membrane lipid traffic Proteomics 9: 914-921, 2009.

16. Geng F and Guo D: Lipid droplets, potential biomarker and metabolic target in glioblastoma. Intern Med Rev (Wash DC): May 3, 2017 (Epub ahead of print). doi: 10.18103/imr.v3i5.443.

17. Bartz R, Zehmer JK, Zhu M, Chen Y, Serrero G, Zhao Y and Liu P: Dynamic activity of lipid droplets: Protein phosphorylation and GTP-mediated protein translocation. J Proteome Res 6: 3256-3265, 2007.

18. Brasaemle DL: Thematic review series: Adipocyte biology. The perilipin family of structural lipid droplet proteins: Stabilization of lipid droplets and control of lipolysis. J Lipid Res 48 : 2547-2559, 2007

19. Dalen KT, Dahl T, Holter E, Arntsen B, Londos C, Sztalryd C and Nebb HI: LSDP5 is a PAT protein specifically expressed in fatty acid oxidizing tissues. Biochim Biophys Acta 1771: 210-227, 2007.

20. Wolins NE, Quaynor BK, Skinner JR, Tzekov A, Croce MA, Gropler MC, Varma V, Yao-Borengasser A, Rasouli N, Kern PA, et al: OXPAT/PAT-1 is a PPAR-induced lipid droplet protein that promotes fatty acid utilization. Diabetes 55 3418-3428, 2006.

21. Yamaguchi T, Matsushita S, Motojima K, Hirose F and Osumi T: MLDP, a novel PAT family protein localized to lipid droplets and enriched in the heart, is regulated by peroxisome proliferator-activated receptor alpha. J Biol Chem 281: 14232-14240, 2006.

22. Gandotra S,Le DourC,Bottomley W,Cervera P, Giral P, Reznik Y, Charpentier G, Auclair M, Delépine M, Barroso I, et al: Perilipin deficiency and autosomal dominant partial lipodystrophy. N Engl J Med 364: 740-748, 2011.

23. Tansey JT, Sztalryd C, Gruia-Gray J, Roush DL, Zee JV, Gavrilova O, Reitman ML, Deng CX, Li C, Kimmel AR and Londos C: Perilipin ablation results in a lean mouse with aberrant adipocyte lipolysis, enhanced leptin production, and resistance to diet-induced obesity. Proc Natl Acad Sci USA 98: 6494-6499, 2001

24. Cao J, Feng XX, Yao L, Ning B, Yang ZX, Fang DL and Shen W: Saturated free fatty acid sodium palmitate-induced lipoapoptosis by targeting glycogen synthase kinase- $3 \beta$ activation in human liver cells. Dig Dis Sci 59: 346-357, 2014.

25. Li F, Gu Y, Dong W, Li H, Zhang L, Li N, Li W, Zhang L, Song Y, Jiang L, et al: Cell death-inducing DFF45-like effector, a lipid droplet-associated protein, might be involved in the differentiation of human adipocytes. FEBS J 277: 4173-4183, 2010.
26. Livak KJ and Schmittgen TD: Analysis of relative gene expression data using real-time quantitative PCR and the 2(-Delta Delta C(T)) method. Methods 25: 402-408, 2001.

27. Bhala N, Younes R and Bugianesi E: Epidemiology and natural history of patients with NAFLD. Curr Pharm Des 19: 5169-5176, 2013.

28. Cao J, Dai DL, Yao L, Yu HH, Ning B, Zhang Q, Chen J, Cheng WH, Shen W and Yang ZX: Saturated fatty acid induction of endoplasmic reticulum stress and apoptosis in human liver cells via the PERK/ATF4/CHOP signaling pathway. Mol Cell Biochem 364: 115-129, 2012.

29. Malhi $\mathrm{H}$ and Gores GJ: Molecular mechanisms of lipotoxicity in nonalcoholic fatty liver disease. Semin Liver Dis 28: 360-369, 2008.

30. Ning B, Bai M and Shen W: Reduced glutathione protects human hepatocytes from palmitate-mediated injury by suppressing endoplasmic reticulum stress response. Hepatogastroenterology 58 : 1670-1679, 2011.

31. Cao SS and Kaufman RJ: Targeting endoplasmic reticulum stress in metabolic disease. Expert Opin Ther Targets 17: 437-448, 2013.

32. Li H, Song Y, Zhang LJ, Gu Y, Li FF, Pan SY, Jiang LN, Liu F, Ye J and Li Q: LSDP5 enhances triglyceride storage in hepatocytes by influencing lipolysis and fatty acid $\beta$-oxidation of lipid droplets. PLoS One 7: e36712, 2012.

33. Kuramoto K, Okamura T, Yamaguchi T, Nakamura TY, Wakabayashi S, Morinaga H, Nomura M, Yanase T, Otsu K, Usuda N, et al: Perilipin 5, a lipid droplet-binding protein, protects heart from oxidative burden by sequestering fatty acid from excessive oxidation. J Biol Chem 287: 23852-23863, 2012.

34. Engin A: Non-alcoholic fatty liver disease. Adv Exp Med Biol 960: 443-467, 2017.

35. Kishikawa $\mathrm{N}$ and Kuroda N: Chemiluminescence assay for the investigation of reactive oxygen species generator. Yakugaku Zasshi 135: 191-196, 2015 (In Japanese).

36. Feldstein AE, Canbay A, Angulo P, Taniai M, Burgart LJ, Lindor KD and Gores GJ: Hepatocyte apoptosis and fas expression are prominent features of human nonalcoholic steatohepatitis. Gastroenterology 125: 437-443, 2003.

37. Schattenberg JM, Galle PR and Schuchmann M: Apoptosis in liver disease. Liver Int 26: 904-911, 2006.

38. Cao Z, Zhang H, Cai X, Fang W, Chai D, Wen Y, Chen H, Chu F and Zhang Y: Luteolin promotes cell apoptosis by inducing autophagy in hepatocellular carcinoma. Cell Physiol Biochem 43: 1803-1812, 2017.

39. Diamantis A, Magiorkinis E, Sakorafas GH and Androutsos G: A brief history of apoptosis: From ancient to modern times. Onkologie 31: 702-706, 2008

40. Granneman JG, Moore HP, Mottillo EP and Zhu Z: Functional interactions between Mldp (LSDP5) and Abhd5 in the control of intracellular lipid accumulation. J Biol Chem 284: 3049-3057, 2009.

41. Wang H, Bell M, Sreenivasan U, Hu H, Liu J, Dalen K, Londos C, Yamaguchi T, Rizzo MA, Coleman R, et al: Unique regulation of adipose triglyceride lipase (ATGL) by perilipin 5, a lipid droplet-associated protein. J Biol Chem 286: 15707-15715, 2011.

42. Mansour M, Schwartz D, Judd R, Akingbemi B, Braden T, Morrison E, Dennis J, Bartol F, Hazi A, Napier I and Abdel-Mageed AB: Thiazolidinediones/PPAR $\gamma$ agonists and fatty acid synthase inhibitors as an experimental combination therapy for prostate cancer. Int J Oncol 38: 537-546, 2011.

This work is licensed under a Creative Commons Attribution-NonCommercial-NoDerivatives 4.0 International (CC BY-NC-ND 4.0) License. 